\title{
Patterns of Rainfall Insurance Participation in Rural India
}

\author{
Xavier Giné, Robert Townsend, and James Vickery
}

\begin{abstract}
Take-up of an innovative rainfall insurance policy offered to smallholder farmers in rural India decreases with basis risk between insurance payouts and income fluctuations, increases with household wealth, and decreases with binding credit constraints. These results are consistent with the predictions of a simple neoclassical model with borrowing constraints. Other patterns are less consistent with the benchmark model. For example, participation in village networks and measures of familiarity with the insurance vendor are strongly correlated with insurance take-up decisions, and riskaverse households are less, not more, likely to purchase insurance. These results may reflect household uncertainty about the product, given their limited experience with it. JEL Codes: O10, O16, G2, G22
\end{abstract}

Insurance markets are growing rapidly in the developing world. As part of this growth, innovative products allow individual smallholder farmers to hedge against agricultural risks, such as drought, disease, and commodity price fluctuations. A World Bank (2005b) volume examines 10 case studies in countries as diverse as India, Malawi, Nicaragua, and Ukraine. Each case study describes

Xavier Giné is an economist in the Development Research Group at the World Bank; his email address is xgine@worldbank.org. Robert Townsend is the Charles E. Merriam Distinguished Service Professor of Economics at the University of Chicago; his email address is rtownsen@uchicago.edu. James Vickery (corresponding author) is an economist at the Federal Reserve Bank of New York; his email address is james.vickery@ny.frb.org. The authors gratefully acknowledge the financial support of the Global Association of Risk Professionals (GARP), the Switzerland State Secretariat for Economic Affairs (SECO), and the World Bank Commodity Risk Management Group (CRMG). They thank researchers at the International Crops Research Institute for the Semi-Arid Tropics (ICRISAT), particularly KPC Rao, for their efforts in collecting the survey data, as well as the staff of BASIX and ICICI Lombard for their assistance. Ulrich Hess and Don Larson of the World Bank provided valuable advice and encouragement, as did Shawn Cole; Ashok Rai; and seminar participants at ICRISAT, the 2007 World Bank Conference on Access to Finance, the 2007 Center for Analytical Finance (CAF) at the Indian School of Business, Hyderabad, the Financial Institutions Center (FIC) at the Wharton School, the Swedish Institute for Financial Research (SIFR) at Stockholm conference on the Indian financial system at Wharton, and the 2007 Center for Economic Policy Research Gerzensee Asset Pricing conference. Paola de Baldomero Zazo, Helene Bie Lilleor, Joan Pina Martí, and Sarita Subramanian provided outstanding research assistance. A supplemental appendix to this article is available at http://wber.oxfordjournals.org.

THE WORLD BANK ECONOMIC REVIEW, VOL. 22, NO. 3, pp. 539-566

doi:10.1093/wber/lhn015

Advance Access Publication October 22, 2008

(C) The Author 2008. Published by Oxford University Press on behalf of the International Bank for Reconstruction and Development / THE WORLD BANK. All rights reserved. For permissions, please e-mail: journals.permissions@oxfordjournals.org 
index insurance, a product whose payouts are linked to a publicly observable index, such as rainfall recorded on a local rain gauge. Advocates argue that index insurance is transparent and inexpensive to administer, enables quick payouts, and minimizes moral hazard and adverse selection problems associated with other risk-coping mechanisms and insurance programs.

These financial innovations hold significant promise for rural households. Shocks to agricultural income, such as a drought-induced harvest failure, generate movements in consumption for households that are not perfectly insured; at the extreme they may lead to famine or death. The evidence suggests that households in developing countries are only partially insured against income shocks (see, for example Townsend 1994; Morduch 1995; and Lim and Townsend 1998). Moreover, weather events tend to affect all households in a local geographic area, making other risk-sharing mechanisms, such as interhousehold transfers and local credit and asset markets, less effective at mitigating the impact of the shock.

Households engage in costly ex ante risk-mitigation strategies to reduce fluctuations in agricultural income. Morduch (1995) summarizes a range of evidence of this kind of household income smoothing. Indian farmers near subsistence level spatially diversify their plots, for example, and devote a larger share of land to lower yielding, traditional varieties of rice and castor. These activities reduce the variability of agricultural revenues, but they do so at the cost of lower average income.

This article studies a particular rainfall insurance product offered in recent years to smallholder farmers in the Andhra Pradesh region of southern India. The product provides a payout based on rainfall during the three phases of the monsoon season. It is inexpensive enough to be accessible to farmers of modest income. A policy covering all three phases of the monsoon costs about 150250 rupees (Rs) (equivalent to $\$ 4-\$ 6$ ). The product is sold to farmers by BASIX, a microfinance institution; rainfall risk is underwritten by the insurance firm ICICI Lombard and its reinsurers.

A basic research question for the study of microinsurance markets is estimating the cross-sectional determinants of household insurance take-up and identifying the impediments to trade that prevent remaining households from participating. After describing the insurance product, this article presents empirical evidence on the determinants of insurance participation based on a household survey implemented by the International Crops Research Institute for the Semi-Arid Tropics (ICRISAT) and the World Bank in late 2004. The article first evaluates take-up patterns against a simple neoclassical benchmark, which predicts that insurance participation is increasing in risk aversion and the variance of risk and decreasing in basis risk between insurance payouts and the risk to be insured. Some evidence consistent with the basis risk prediction is found: households that historically plant a high share of castor and groundnut, the two crops for which contracts are designed, are more likely to purchase insurance. Take-up rates are also higher among wealthy households and lower 
among households identified as credit constrained. These findings are consistent with an extension of the benchmark model to include borrowing constraints.

Other evidence is more difficult to reconcile with the benchmark model. Among the most significant determinants of insurance take-up are variables measuring the household's degree of familiarity with the insurance vendor, such as whether the household is already a BASIX customer. Participation is also higher among households that are members of the village Gram Panchayat (local council) and those that are connected to other village networks, especially when a larger number of other members or the household's primary network also buy insurance. Risk-averse households are somewhat less likely to purchase rainfall insurance, not more likely, as the neoclassical framework would suggest. This result is concentrated among households that are unfamiliar with BASIX or do not use other types of insurance.

These finding can be interpreted to suggest that many households are uncertain about the insurance product, leading risk-averse households, households with higher costs of evaluating new technologies, and households that are less familiar or place less trust in the insurance provider to eschew purchasing insurance. This interpretation is consistent with qualitative evidence. Lack of understanding about the product was the most common explanation cited by households for not purchasing insurance, and a significant fraction of purchasers cited "advice from others" as a reason for their decision to buy.

These results represent a first step toward understanding the barriers to household participation in microinsurance contracts. Some of the results may reflect the process used to market the product. The results on the role of networks and familiarity with BASIX, for example, may partly reflect the more intensive marketing of the insurance product to village opinion leaders and existing customers. Ongoing research by the authors is examining insurance participation using a randomized field experimental design that explicitly controls for the type of information and marketing received by households. This is also the approach taken by Cole, Tobacman, and Topalova (2008), who study take-up of a rainfall insurance product by households in Gujarat. They find that wealth is positively correlated with insurance take-up. They also find that the framing of the insurance product has a significant impact on the household's decision to purchase insurance.

Section I outlines the concept of index insurance, and section II describes the insurance contract features and related institutional details. Section III discusses theoretical determinants of insurance participation and introduces the hypotheses to be tested. Section IV discusses the survey and presents summary statistics. Section V presents empirical results, and section VI offers concluding remarks.

\section{The Promise of Index Insurance}

Index insurance provides a payout based on the realization of a publicly verifiable aggregate index, such as rainfall at a local rain gauge or an areawide 
measure of crop yields. The goal of such insurance is to insulate income and consumption against aggregate shocks that are plausibly exogenous to the household.

Index insurance minimizes or eliminates moral hazard and adverse selection problems that otherwise distort behavior in insurance markets. It does so because payouts are determined by exogenous information that is unaffected by either unobserved household characteristics (adverse selection) or ex post household decisions (moral hazard). A properly designed index has at least five desirable features: it is transparent and verifiable to policyholders; its calculation is not vulnerable to tampering or manipulation; its probability distribution can be accurately estimated, so that the product can be appropriately priced and the expected return assessed by households; it can be measured inexpensively and in a timely fashion; and the realization of the index, or a transformation of the index, is highly correlated with household income and consumption risk.

The most widespread index-type insurance available in India is the government-operated National Agriculture Insurance Scheme, which provides a payout based on measured area-level yields on individual crops. In participating states, farmers are required to purchase the insurance if they take a crop loan from a formal financial institution; other farmers can purchase the insurance voluntarily (Kalavakonda and Mahul 2005; Mishra 1996). (For more information, see the supplemental appendix to this article, available online at http://wber.oxfordjournals.org, which describes the insurance in more detail and summarizes its costs and benefits relative to rainfall insurance.)

A necessary feature of any insurance contract is that payoffs be correlated with household income and consumption. The evidence suggests that deficient rainfall is a key risk faced by rural Indian households. The supplemental appendix presents self-reported rankings from survey data of the importance of different risks faced by households. An overwhelming proportion of households (88 percent) cite drought as the most important risk they face. Crop failure for reasons other than drought and crop disease are the second and third most frequently cited reasons. Consistent with these self-reports, the World Bank (2005a) estimates that a severe drought would reduce rice yields by 45 percent in Ananthapur and 26 percent in Mahbubnagar, a potentially devastating loss of income for households near subsistence level.

\section{Policy Design and Marketing}

The rainfall insurance product studied here is designed to insure farmers in semiarid tropical areas of India against deficient rainfall. It was developed by the general insurer ICICI Lombard, with technical assistance from the World Bank. ICICI Lombard partners with local financial institutions, which market the product to farmers. In the Ananthapur and Mahbubnagar districts of 
FigURE 1. Structure of Insurance Contract

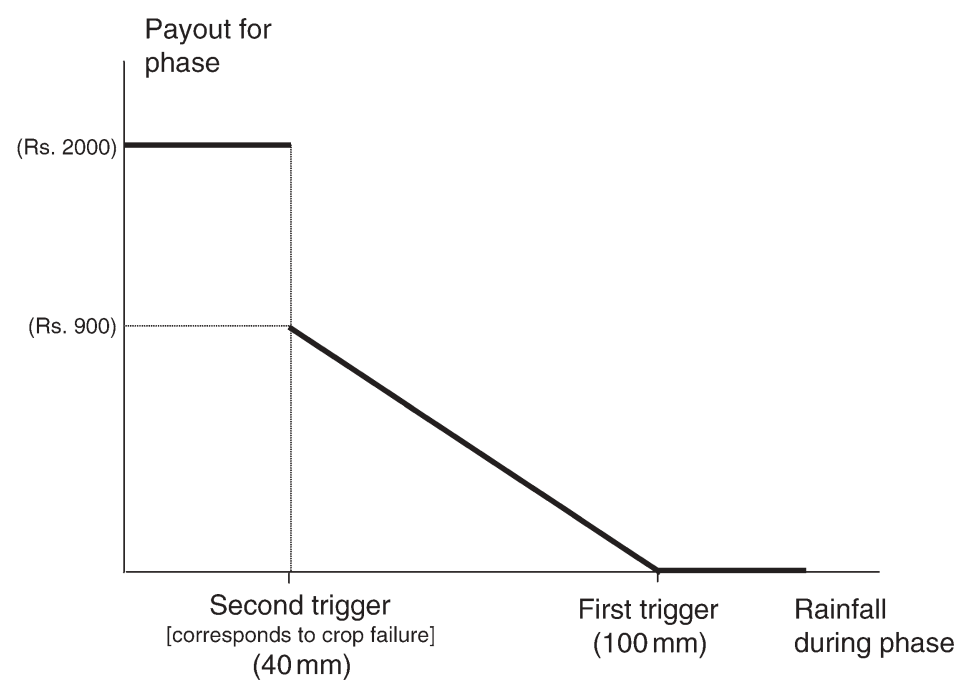

Andhra Pradesh, where the product was piloted in 2003 and 2004, this role is performed by BASIX, a microfinance institution.

\section{Contract Design}

Rainfall insurance policies for 2004 were designed for the two main cash crops in the region: castor and groundnut. ${ }^{1}$ These crops are more profitable than food crops, such as pulses, but they are also more sensitive to drought. Because the seeds are relatively expensive, some farmers use crop loans to purchase them; but when the harvest fails these loans are often difficult to repay (Hess 2002).

The coverage for all policies is the monsoon season-the prime cropping season-which runs from June to September. The insurance contract divides the season into three phases, sowing, podding/flowering, and harvest (figure 1). An upper and lower rainfold threshold is specified for each phase. The policy pays zero if accumulated rainfall exceeds the upper threshold; otherwise, the policy pays a fixed amount for each millimeter of shortfall relative to the upper threshold, until the lower threshold is reached. If rainfall falls below the lower threshold, the policy pays a fixed (higher) payout. The total payout is the sum of payouts across the three phases.

The timing of phases, thresholds, and other parameters of the contract were determined using the PNUTGRO crop model (Gadgil, Rao, and Rao 2002) and interactions with farmers. The upper threshold corresponds to the crop's

1. This discussion draws in part on World Bank (2005b) and Giné and others (2005). Cole and Tufano (2007) present additional details about the product background and BASIX's commercial incentives in marketing rainfall insurance policies. 
water requirement; the second trigger is intended to equal the water requirement necessary to avoid complete harvest failure.

The policy premium was initially benchmarked on projected payouts using historical rainfall data (at least 25 years of data for each rain gauge were used). The premium was calculated as the sum of the expected payout, 25 percent of its standard deviation, 1 percent of the maximum sum insured in a year, plus a 25 percent administrative charge and 10.2 percent government service tax. In some cases the premium dictated by this formula was then reduced, because it was believed to exceed farmers' willingness to pay. The policy was targeted toward small and medium-size farmers with 2-10 acres of land. Sales were not limited to this group, however; any household in the targeted villages was eligible to purchase the insurance product.

\section{Example}

Mahbubnagar district includes three mandals (counties) with reference weather stations (Atmakur, Mahbubnagar, and Narayanpet) against which contracts are written. In Narayanpet the premium for a policy covering all three phases of the monsoon was Rs 200 in 2004. One policy is considered equivalent to one acre of coverage. In 2004 the start date for the monsoon was set as June 10, and the first phase was 35 days long. Narayanpet received 12 millimeters of rain in the first phase, 84 millimeters of rain in the second phase, and 177 millimeters of rain in the third phase (table 1). This resulted in a maximum lump sum payout of Rs 1,500 in the first phase, as accumulated rainfall fell below the lower trigger of 60 millimeters. Rainfall during the second phase was also deficient but exceeded the lower trigger level, resulting in a payout of Rs 240 per acre insured [240 $=(100$ millimeters -84 millimeters $) \times 15]$. Rainfall exceeded the upper threshold value in the third phase. Insured households in Narayanpet thus received total payouts of Rs 1,740 per policy.

\section{BASIX Distribution and Marketing}

BASIX has extensive local distribution networks, because it also provides microfinance loans to households in villages where the insurance product is marketed. The insurance product was piloted in 2003 in two villages in Mahbubnagar; it was expanded to 43 pilot villages in Mahbubnagar and Ananthapur in 2004.

BASIX used four criteria to determine whether a village was suitable for insurance marketing in 2004: the presence of existing BASIX customers (to ensure some degree of trust in the institution); 200-300 acres of groundnut or castor crops; a reasonable number of farms with 2-10 acres of land; and a village location within 20 kilometers of the nearest rainfall reference station (to minimize basis risk). Because of time constraints, BASIX offered insurance in only a subset of villages meeting these four criteria.

BASIX's strategy was to first explain the insurance product to a trusted opinion leader, who then functioned as a motivator, informing other 
TA B LE 1. Terms and Payouts of Rainfall Insurance Contracts in Mahbubnagar District, Andhra Pradesh, 2004

\begin{tabular}{|c|c|c|c|c|c|c|c|c|}
\hline $\begin{array}{l}\text { Mandal } \\
\text { (county) }\end{array}$ & $\begin{array}{l}\text { Premium per } \\
\text { acre (rupees) }\end{array}$ & Phase $^{a}$ & $\begin{array}{l}\text { First trigger level } \\
\text { (millimeters) }\end{array}$ & $\begin{array}{l}\text { Payout per } \\
\text { millimeter deficient } \\
\text { rain (rupees) }\end{array}$ & $\begin{array}{c}\text { Second trigger } \\
\text { level (millimeters) }\end{array}$ & $\begin{array}{c}\text { Maximum } \\
\text { lump-sum payout } \\
\text { (rupees) }\end{array}$ & $\begin{array}{l}\text { Actual rainfall } \\
\text { (millimeters) }\end{array}$ & $\begin{array}{l}\text { Actual payout } \\
\text { per acre } \\
\text { (rupees) }\end{array}$ \\
\hline \multirow[t]{3}{*}{ Atmakur } & \multirow[t]{3}{*}{250} & 1 & 60 & 10 & 25 & 1,500 & 94.2 & 0 \\
\hline & & 2 & 100 & 15 & 5 & 2,000 & 90.0 & 150 \\
\hline & & 3 & 75 & 15 & 30 & 2,500 & 184.0 & 0 \\
\hline \multirow[t]{2}{*}{ Mahbubnagar } & \multirow[t]{2}{*}{150} & 1 & 60 & 10 & 20 & 1,500 & 31.0 & 290 \\
\hline & & 2 & 100 & 15 & 50 & 2,000 & 96.0 & 60 \\
\hline \multirow[t]{3}{*}{ Narayanpet } & \multirow[t]{3}{*}{200} & 1 & 60 & 10 & 20 & 1,500 & 12.0 & 1,500 \\
\hline & & 2 & 100 & 15 & 40 & 2,000 & 84.0 & 240 \\
\hline & & 3 & 75 & 15 & 50 & 2,500 & 177.0 & 0 \\
\hline
\end{tabular}

aphase 1: June 10-July 14; phase 2: July 15-August 28; phase 3: August 29-October 12.

Source: Authors' analysis based on 2004 ICRISAT and World Bank survey data and Indian Meteorological Department rainfall data. 
households about the product and a marketing meeting to be held a few days later. BASIX provided a general introduction to the insurance product at the marketing meeting. Policies were sold at the meeting and at individual visits to interested households following the meeting. BASIX agents generally spent one day in each village to market and sell the product.

BASIX representatives ascribed differences in insurance take-up rates across pilot villages to the choice of motivator (particularly the motivators' understanding of the product and their status in the village), the extent of BASIX's market presence, the number of rainy spells before the day of marketing, whether it was raining on the day of marketing (it being hard to sell rainfall insurance on a rainy day), and the liquid assets of farmers on the day of marketing. These factors varied substantially. In some villages farmers had just received payments for their milk delivery and therefore had cash on hand; in other villages, particularly in Ananthapur, government subsidies for groundnut seeds had recently been made available, and most farmers had spent their savings purchasing seeds.

Based on feedback from farmers and BASIX field agents, the rainfall insurance contract design was refined in two important respects between 2004 and 2006. First, separate castor and groundnut policies were combined into a single policy for each rain gauge, to simplify marketing and appeal to farmers growing other crops and to improve benefits for policyholders. Second, the start of the first phase was changed from a fixed calendar date (June 10) to the date by which at least 50 millimeters of rain had fallen since June 1 .

Giné, Townsend, and Vickery (2007) present more information on the 2006 contracts and analyze the statistical properties of contract returns by constructing a time series of putative insurance returns using historical rainfall data. They find that the insurance policy insures primarily against severe rainfall events, paying out a positive return in only 11 percent of phases and providing a maximum rate of return of about 900 percent.

In 2003 rainfall insurance was sold to 148 farmers in two villages, mostly to members of borewell users associations. ${ }^{2}$ The number of purchasers rose to 315 farmers across 43 pilot villages in 2004. Policies sold covered 570 acres of crop, insuring Rs 3,409,200, equivalent to Rs 10,822 per farmer (about \$240). (For a table showing insurance participation in 2003-04 across survey mandals, see section S3 of the supplemental appendix.)

\section{Determinants of Insurance Participation: Theoretical PREDICTIONS}

What does economic theory predict regarding the determinants of insurance market participation? In a simple setting without asymmetric information, a

2. A borewell user association is a group of households that jointly use and maintain a water bore or set of bores. 
household's willingness to pay for an insurance contract will be increasing in risk aversion, the expected insurance payout, and the size of the insured risk and decreasing in basis risk (in other words, increasing in the correlation between the insurance payout and the risk to be insured or, more generally, the household's consumption risk). This is referred to in the remainder of this article as the benchmark model of insurance participation. ${ }^{3}$

Many households remain uninsured against significant income risks (many U.S. households do not have health insurance, for example). Deviating from the full-information benchmark, a large body of literature has considered adverse selection and moral hazard as potential explanations for barriers to trade in insurance (see, for example, Abbring, Chiappori, and Pinquet 2003; Cawley and Philipson 1996; and Rothschild and Stiglitz 1976). Empirical evidence for asymmetric information models of insurance is mixed. For example, Cawley and Philipson (1996) find that conditional on observables, life insurance premia are decreasing in the quantity of insurance purchased, a result that it is at odds with the separating equilibrium in Rothschild and Stiglitz (1976).

Models of adverse selection and moral hazard are of limited applicability to the rainfall insurance contract studied here. Historical rainfall patterns at mandal rain gauges are public information, ruling out adverse selection, while moral hazard presents a problem only to the extent that households tamper with the measurement of rainfall at the gauge. There is no evidence suggesting that this is a problem in practice: a World Bank representative who has visited Indian Meteorological Department weather stations reports that they are secure, fenced locations and that rainfall measurements are checked for inconsistencies.

Mulligan and Philipson (2003) introduce fixed participation costs to a benchmark insurance demand model. They argue that such costs help account for patterns such as the positive correlation between wealth and insurance participation identified by Cawley and Philipson (1996).

It is not obvious that any significant fixed costs apply in the setting examined here. Administrative loadings are proportional to the amount insured, and there is no discount for multiple policies. It is possible that because insurance policies are indivisible, it may be difficult for poor households to purchase even a single policy. There may also be other, nonmonetary fixed costs, such as the time cost of attending the marketing meeting or the cognitive costs associated with understanding the product.

\section{Hypotheses}

Four hypotheses are presented here. Each is tested in the next section.

Hypothesis 1: Insurance participation is higher when risk aversion is high, basis risk is low, and the risk to be insured is large.

3. The appendix presents a simple parametric example of this benchmark model for a household with mean-variance expected utility. The model yields a simple closed-form expression for the household's willingness to pay that illustrates the four comparative statics predictions listed above. 
This first hypothesis is simply that insurance participation decisions are consistent with the benchmark model described above.

Hypothesis 2: Insurance participation is higher when the household's subjective expectation for future rainfall is low.

Historical rainfall patterns are publicly observable, which suggests that households may share common expectations about the distribution of insurance payouts. To the extent that beliefs differ, households that expect lower rainfall would view the insurance contract as having a higher expected return and would therefore be more likely to purchase insurance.

Hypothesis 3: Insurance participation is higher when households are less credit constrained (that is, when the shadow value of liquid assets is lower).

Financial constraints potentially play a key role in insurance participation decisions. On the one hand, credit-constrained households may value the reduction in income volatility provided by insurance more highly, because they have less ability to smooth consumption ex post. On the other hand, at the start of the monsoon season, when insurance purchase decisions are made, credit-constrained rural households have limited funds with which to purchase seeds, fertilizer, and other materials needed for sowing. Even if such households are risk averse and would benefit from insurance, the shadow value of liquid assets may be extremely high at such times, making the purchase of insurance unattractive.

The intuition of this second mechanism is illustrated through an extension of the benchmark model in the appendix. It considers a household with meanvariance utility, so that in the baseline model risk aversion and willingness to pay for insurance are independent of wealth. The extension assumes that the household has limited funds, which can be used to purchase insurance or invest in sowing. Willingness to pay for insurance is unambiguously lower when credit constraints bind; within that region it is uniformly increasing in wealth. This result reflects a simple intuition: the more binding are credit constraints, the higher is the shadow value of financial wealth, reflecting the high marginal product of the alternative use of those funds (investment in sowing).

This result may not obtain unambiguously in a multiperiod setting, because credit- constrained households would also place higher value ex post on the smoothing of income provided by insurance and because such households are more likely to be constrained at the beginning of future monsoons. (Building a fully specified dynamic model is an interesting challenge for future research.) This suggests that the correct sign of the relation between credit constraints and insurance demand is ambiguous and must be established empirically.

Hypothesis 4: Insurance participation is lower when trust in the insurance vendor and understanding of the product is weak and when networks for disseminating information about the product are poor. 
The empirical setting also relates closely to the literature on technology adoption and diffusion (Griliches 1957; Feder, Just and Zilberman 1985). This study examines a new financial product: households in the sample have been offered the opportunity to purchase rainfall insurance at most only once previously. Even with the help of the BASIX agent, the household may be uncertain about the contract design or the timing or magnitudes of payouts. Alternatively, the household may not fully trust the insurer to pay out on claims. Although the model is not formally extended to model these factors, three interrelated hypotheses are proposed relating to take-up of a new product that is not well understood by households.

Hypothesis $4 a$ : In an environment in which a product is not well understood, households will draw inferences based on the degree of experience and familiarity with the vendor and their trust in it.

Hypothesis 4b: Households are likely to rely on information gleaned from social networks, such as whether other trusted farmers also purchase insurance.

Hypothesis $4 c$ : Households with greater cognitive ability to understand the product are more willing to experiment with it. Younger and more educated household heads will understand the product more easily and be more likely to purchase it.

\section{The SuRvey}

The data come from a household survey conducted after the 2004 monsoon and designed to study households' experiences with ICICI Lombard rainfall insurance. The authors developed the survey questions; ICRISAT conducted the survey in late 2004.

The survey sampling frame is a census of landowner households across 37 villages in Ananthapur and Mahbubnagar. The 25 villages in which at least five households purchased insurance in 2004 were included. The other 12 villages had been identified by BASIX as being suitable for insurance marketing, but no policies had been sold there because of time constraints in the marketing process. Data in these control villages are not used in this paper.

Among the 25 villages, a stratified random sample of households was selected, in order to survey as many purchasers of insurance as possible. Included were all households that purchased insurance ( 267 households), a random sample of households that attended an insurance marketing meeting but did not purchase insurance ( 233 households), and households that did not attend a marketing meeting ( 252 households). The total sample of 752 households was drawn from a population of 5,805 landowning households in the 25 villages. The take-up rate of the insurance product was low, at just 4.6 percent $(267 / 5,805)$, reflecting the short history of the product.

The survey nonresponse rate was extremely low. None of the 267 insurance purchasers refused to participate, and the frequency of nonresponse among nonpurchasers was close to zero. (This in part reflects the fact that the survey was administered after the end of the monsoon, when households were less 
busy.) The sample of 267 purchasers represents 85 percent of the 315 households across all villages that purchased rainfall insurance from BASIX in 2004.

In most of the regressions, the dependent variable is purchased insurance. As this variable is also stratified, the sampling approach is an example of choicebased sampling. A weighted probit regression is estimated using the sampling weights discussed above to recover consistent estimates of the slope coefficients, following Manski and Lerman (1977).

\section{Summary Statistics and Variable Construction}

Full-sample averages are weighted by population and thus are close to nonbuyer averages, given the low take-up rate (table 2). For the 25 households for which data are missing for one or more variables, missing values are iteratively imputed as a function of other variables. No single variable is missing more than 11 times; the empirical results are almost unchanged if the sample is restricted to households without missing data rather than imputing missing values. (Full details on the construction of each variable are presented in the supplemental appendix.)

Demographic and wealth data confirm that the sample consists of poor and middle-income smallholder farmers. Mean landholdings are 5.8 acres (median landholdings are 4.0 acres). Household heads have an average of 3.3 years of formal education, although the median household head has no formal education. Nearly all (97 percent) household heads have spent their entire life in the village. Mean household liquid assets-the sum of cash, bank account deposits, jewelry, silver, gold, revolving funds, and miscellaneous liquid assets-are Rs 14,100, equivalent to $\$ 313$; median household liquid assets are Rs 8,300 equivalent to $\$ 184)$.

There are significant differences between the characteristics of insurance buyers and those of nonbuyers. Buyers are less risk averse and report owning about 50 percent more land and nearly twice the liquid assets of nonbuyers. About a third of insurance purchasers but just 4 percent of the population as a whole belong to borewell user associations. At the start of the monsoon 46 percent of buyers but just 7 percent of the overall population had outstanding credit from BASIX. Each of these differences in means is statistically significant at the 5 percent level.

Several variables are intended to elicit parameters of the utility function of the household head. The variable risk aversion is measured on a $0-1$ scale. It is constructed from a game in which the household head chooses between a series of gambles indexed by increasing risk and return; the household is then given a cash payout of $0-$ Rs 200 based on its response and the outcome of a coin toss. A related question is used to elicit a dummy variable for ambiguity aversion.

The variable patience indicates the proportionate amount a household head must receive today for it to be indifferent to a fixed amount promised in one 
Table 2. Summary Statistics

\begin{tabular}{|c|c|c|c|c|c|c|c|}
\hline Variable & Buyers & Nonbuyers & $\begin{array}{c}\text { Level of significance } \\
\text { of difference, if any } \\
\text { (percent) }\end{array}$ & Full sample & Standard deviation & Minimum & Maximum \\
\hline \multicolumn{8}{|l|}{ Utility function and beliefs } \\
\hline Risk aversion $^{a}$ & 0.733 & 0.829 & 1 & 0.824 & 0.190 & 0.000 & 1.000 \\
\hline Ambiguity aversion ${ }^{a}$ & 0.507 & 0.553 & & 0.551 & 0.498 & 0.000 & 1.000 \\
\hline Patience & 0.830 & 0.801 & 5 & 0.802 & 0.135 & 0.300 & 1.000 \\
\hline Pessimism about insurance return & 0.334 & 0.308 & & 0.309 & 0.310 & 0.000 & 1.000 \\
\hline \multicolumn{8}{|l|}{ Basis risk } \\
\hline Use accumulated rainfall to decide when to sow ${ }^{\mathrm{a}}$ & 0.052 & 0.076 & & 0.075 & 0.264 & 0.000 & 1.000 \\
\hline Percent of land used for groundnut & 0.216 & 0.225 & & 0.224 & 0.348 & 0.000 & 1.000 \\
\hline Percent of land used for castor & 0.263 & 0.252 & & 0.252 & 0.314 & 0.000 & 1.000 \\
\hline \multicolumn{8}{|l|}{ Credit constraints } \\
\hline Household is constrained $^{\mathrm{a}}$ & 0.760 & 0.811 & & 0.808 & 0.394 & 0.000 & 1.000 \\
\hline \multicolumn{8}{|l|}{ Leadership/networks } \\
\hline Member borewell user association ${ }^{\mathrm{a}}$ & 0.345 & 0.022 & 1 & 0.037 & 0.189 & 0.000 & 1.000 \\
\hline "Progressive" household ${ }^{\mathrm{a}}$ & 0.513 & 0.306 & 1 & 0.316 & 0.465 & 0.000 & 1.000 \\
\hline Member Gram Panchayet ${ }^{\mathrm{a}}$ & 0.041 & 0.016 & & 0.018 & 0.132 & 0.000 & 1.000 \\
\hline $\begin{array}{l}\text { Number of other groups household is member of } \\
\text { Knowledge of insurance and BASIX }\end{array}$ & 1.097 & 0.836 & 1 & 0.848 & 0.745 & 0.000 & 4.000 \\
\hline Past credit from BASIX ${ }^{\mathrm{a}}$ & 0.303 & 0.030 & 1 & 0.043 & 0.203 & 0.000 & 1.000 \\
\hline Has other insurance ${ }^{a}$ & 0.753 & 0.553 & 1 & 0.562 & 0.496 & 0.000 & 1.000 \\
\hline \multicolumn{8}{|l|}{ Income (during monsoon) } \\
\hline Farming income & 55.538 & 29.605 & 1 & 30.801 & 178.622 & 0.000 & $5,621.360$ \\
\hline Nonfarming income & 3.092 & 3.096 & & 3.096 & 3.301 & 0.000 & 40.000 \\
\hline \multicolumn{8}{|l|}{ Wealth (beginning of monsoon) } \\
\hline Mean liquid savings (Rs 000s) & 22.952 & 13.500 & 1 & 13.936 & 18.761 & 0.000 & 453.000 \\
\hline Median liquid savings (Rs 000s) & 14.800 & 8.000 & 1 & 8.000 & & & \\
\hline Total mean wealth (Rs 000s) & 558.668 & 346.183 & 1 & 355.987 & 504.892 & 21.400 & $21,360.500$ \\
\hline Total median wealth (Rs 000s) & 349.550 & 228.000 & 1 & 232.250 & & & \\
\hline
\end{tabular}


TABle 2. Continued

\begin{tabular}{|c|c|c|c|c|c|c|c|}
\hline Variable & Buyers & Nonbuyers & $\begin{array}{l}\text { Level of significance } \\
\text { of difference, if any } \\
\text { (percent) }\end{array}$ & Full sample & Standard deviation & Minimum & Maximum \\
\hline Landholdings (acres) & 8.661 & 5.663 & 1 & 5.801 & 4.952 & 0.300 & 79.500 \\
\hline $\begin{array}{l}\text { percent of cultivated land that is irrigated } \\
\text { Other variables }\end{array}$ & 0.495 & 0.270 & 1 & 0.280 & 0.405 & 0.000 & 2.200 \\
\hline Education of household head (years) & 5.301 & 3.179 & 1 & 3.277 & 4.425 & 0.000 & 18.000 \\
\hline Age of household head & 43.642 & 47.060 & 1 & 46.902 & 11.437 & 21.000 & 80.000 \\
\hline Gender of household head ( $1=$ male $)$ & 0.936 & 0.920 & & 0.921 & 0.270 & 0.000 & 1.000 \\
\hline Household size & 6.674 & 6.485 & 10 & 6.494 & 2.808 & 1.000 & 17.000 \\
\hline Unweighted number of observations & 267 & 485 & & 752 & & & \\
\hline Weighted number of observations & 267 & 5538 & & 5805 & & & \\
\hline
\end{tabular}

${ }^{\mathrm{a}}$ A dummy variable where $1=$ yes.

Source: Authors' analysis based on 2004 ICRISAT and World Bank survey data. 
month's time. The average for this variable is 0.8 , suggesting a high monthly discount rate for the households in the sample.

The variable pessimism about insurance return measures household pessimism regarding the start of an average monsoon season. Households are asked to assess the probability of the monsoon starting after several different dates. The household head's subjective probability density function for the start of the monsoon is estimated from these responses. The pessimism variable is the area under this density function one standard deviation or more to the right of the historical average start of the monsoon season (a larger value thus represents more weight on a later monsoon start).

The variable credit constraints is a proxy for whether the household is credit constrained, based on the household's explanation of why it does not have one more loan. If the household cites a supply-side reason, such as "lack of collateral" or "bank will not give additional loan," this variable is set equal to 1. It is set equal to 0 if the household responds "no need for credit," "do not like to be in debt," or "other."

\section{Empirical Results}

Households that attended a marketing meeting were asked to provide up to three reasons for their decision to purchase BASIX rainfall insurance, ranked in order of importance (table 3). "Security/risk reduction" was the most popular response, followed by "need harvest income"; 65 percent of households cited one of these explanations as the most important reason for purchasing insurance. Responses also indicated the role of networks and learning: "advice from progressive farmers," "other trusted farmers purchased insurance," and "advice from village officials" together account for 19 percent of the weighted responses. Some 12.5 percent of respondents cited either the high expected payout or low premium of the insurance. A small fraction (5.7 percent) of households reported purchasing insurance because of reasons related to "luck."

The most frequently cited reason for not purchasing the product was that the consumer did not understand it (25 percent of weighted responses). Some 21 percent of respondents stated that the household did not have sufficient cash or credit to pay the premium (this finding is consistent with the hypothesis that lack of credit constrains insurance participation). Nearly 24 percent of respondents cited responses related to basis risk ("rain gauge is too far away," "household does not grow castor or groundnut"). Some 16.6 percent of weighted respondents stated that the insurance was too expensive (14.1 percent of respondents) or the payouts too small (2.5 percent of respondents). Only a small percentage of households ( 2.5 percent) stated they had no need for insurance against rainfall risk.

Many of these qualitative responses match well with the benchmark model of insurance participation under symmetric information: the degree of risk reduction, the expected payout relative to the premium, and the degree of basis 
Taвle 3. Self-Reported Reasons for Purchasing Rainfall Insurance (percent of total responses)

\begin{tabular}{|c|c|c|c|c|}
\hline Reason & Primary reason & Secondary reason & Tertiary reason & Weighted sum \\
\hline \multicolumn{5}{|l|}{ Reason for purchasing rainfall insurance } \\
\hline Security/risk reduction & 139 & 53 & 20 & 40.1 \\
\hline Need harvest income & 25 & 62 & 12 & 15.6 \\
\hline Advice from progressive farmers & 17 & 28 & 12 & 8.8 \\
\hline High payout & 9 & 27 & 11 & 6.8 \\
\hline Other trusted farmers purchased insurance & 16 & 11 & 16 & 6.3 \\
\hline Low premium & 17 & 10 & 6 & 5.7 \\
\hline Advice from village officials & 9 & 14 & 3 & 4.3 \\
\hline Product was well explained & 5 & 9 & 4 & 2.7 \\
\hline High percentage of castor & 7 & 2 & 6 & 2.3 \\
\hline High percentage of groundnut & 4 & 5 & 2 & 1.8 \\
\hline Total & 252 & 243 & 113 & 100.0 \\
\hline \multicolumn{5}{|l|}{ Reason for not purchasing rainfall insurance } \\
\hline Do not understand the product & 45 & 59 & 11 & 24.9 \\
\hline No cash/credit to pay the premium & 58 & 21 & 11 & 21.4 \\
\hline Too expensive & 32 & 23 & 7 & 14.1 \\
\hline No castor or groundnut & 13 & 6 & 1 & 4.9 \\
\hline Do not trust BASIX & 5 & 8 & 2 & 3.1 \\
\hline Other & 6 & 7 & 0 & 3.0 \\
\hline No need & 6 & 4 & 1 & 2.5 \\
\hline Payouts too small & 3 & 7 & 4 & 2.5 \\
\hline Dislike insurance & 4 & 7 & 1 & 2.5 \\
\hline Purchased in 2003 but not satisfied & 2 & 1 & 0 & 0.8 \\
\hline Purchased in 2003 but no payout & 2 & 1 & 0 & 0.8 \\
\hline Cloud seeding promised by government & 0 & 1 & 3 & 0.5 \\
\hline Total & 214 & 184 & 50 & 100.0 \\
\hline
\end{tabular}

Reason for purchasing rainfall insurance

Source: Authors' analysis based on 2004 ICRISAT and World Bank survey data. 
risk are important factors households consider when making purchase decisions. Two types of responses are inconsistent with the benchmark model. First, a significant proportion of households that purchase insurance do so on the advice of trusted farmers or village leaders; conversely, 25 percent of nonpurchasers cite a lack of understanding of the product. Second, a significant proportion of nonpurchasers cite a lack of liquid funds or credit to pay for the premium, suggesting the importance of credit constraints.

\section{Regression Estimates}

A reduced-form probit regression model of insurance participation is estimated. The dependent variable is equal to 1 if the household purchases BASIX rainfall insurance in 2004 and 0 otherwise (table 4).

The first column of results normalizes coefficients to reflect the marginal effect of a one-unit change in the explanatory variable on the probability of insurance purchase. For expository purposes, in column 2, the same results are provided after dividing the coefficients by the population mean participation rate of 0.046; these coefficients indicate the percentage change in the probability of take-up for a one-unit shock to the relevant covariate (a coefficient of 1 indicates that a one-unit shock to the explanatory variable doubles the probability of insurance participation for a household whose initial participation probability equals the population average).

Benchmark model (bypothesis 1). A first prediction of the benchmark model is that insurance participation is decreasing in basis risk between payouts and household income and increasing in the size of the risk to be insured. Coefficients in table 4 under basis risk appear consistent with these predictions. In particular, two variables are included that measure the proportion of cultivated land used for castor and groundnut the previous year. As these are the two crops against which policies are written, the basis risk from using insurance to hedge rainfall risk is presumably lower when these crops predominate. Consistent with this prediction, the signs on both percentage groundnut and percentage castor are positive, and both are statistically significant at the 1 percent level. The coefficients in column 2 show that for a household at the population take-up probability of 0.046 , moving from growing no groundnut to growing all groundnut increases the probability of purchasing insurance in 2004 by 59 percent ( 34 percent for castor).

A caveat on these findings is that crop choice is endogenous and there is no econometric instrument for the crop types grown. It is thus possible that an omitted third factor drives both the percentage of castor and groundnut grown and the decision to purchase insurance. For example, progressive or informed farmers may be more likely to grow high-yielding cash crops and more likely to purchase insurance. An alternative variable for measuring basis risk would be distance to rain gauge or some other direct measure of the difference in weather between the farm and the weather station. This approach was not adopted here, because only a small number of villages is studied and because 
Table 4. Baseline Estimates

Marginal effects

scaled by population

Estimate

Marginal effects take-up rate

Utility function

Risk aversion

Ambiguity aversion

$\begin{array}{rr}-0.011(1.84)^{*} & -0.246(1.84)^{*} \\ -0.000(0.07) & -0.004(0.07) \\ 0.009(0.95) & 0.193(0.95)\end{array}$

Patience

Beliefs about return on insurance

Pessimism about insurance return

Basis risk

Use accumulated rainfall to decide when to sow

Percent cultivated land used for groundnut

Percent cultivated land used for castor

Wealth and credit constraints

$\log$ (wealth in rupees at start of monsoon)

Log (landholdings, start of monsoon)

$F$-test: wealth and land ( $p$-value)

Percent of cultivated land that is irrigated

Household is credit constrained ( $1=$ yes)

Familiarity with insurance and BASIX

Borewell user association member $(1=$ yes $)$

Credit from BASIX $(1=$ yes $)$

Has other insurance $(1=$ yes $)$

Technology diffusion/networks

Progressive household

$0.004(1.19)$

$0.094(1.19)$

$-0.000(0.05)$

$-0.005(0.05)$

$0.027(3.40) * * *$

$0.595(3.40)^{* * *}$

$0.016(2.84) * * *$

$0.338(2.84) * * *$

Member Gram Panchayat

$0.004(1.19)$

$0.079(1.19)$

$0.002(0.70)$

$0.02 * *$

$0.054(0.70)$

$0.003(1.12)$

$0.02 * *$

$-0.014(3.29)^{* * *}$

$0.075(1.12)$

$-0.299(3.29)^{* * * *}$

$0.368(4.70) * * *$

$7.996(4.70) * * *$

$0.066(4.83) * * *$

$1.438(4.83)^{* * * *}$

$0.003(1.35)$

$0.074(1.35)$

Number of other groups household is member of

Number of well-known households

$0.007(2.12) * *$

$0.144(2.12) * *$

$0.081(2.87) * * *$

$1.759(2.87) * * *$

$0.007(3.51)^{* * * *}$

$0.161(3.51)^{* * * *}$

$0.000(0.36)$

$0.003(0.36)$

Number of well-known households that bought

$0.006(5.06) * * *$

$0.124(5.06)^{* * *}$

insurance

Other covariates

Log (education of household head in years)

Log (age of household head)

$0.001(1.09)$

$0.029(1.09)$

$-0.015(2.59) * * *$

$-0.318(2.59)^{* * * *}$

Household head spent whole life in village $(1=$ yes $)$

Gender of household head ( $1=$ male)

$-0.030(1.79)^{*}$

$-0.654(1.79)^{*}$

$-0.008(1.37)$

$0.002(0.41)$

Log (household size)

$-0.184(1.37)$

$0.035(0.41)$

Village dummy variables

Number of observations

Pseudo $R^{2}$

yes

752

yes

752

0.44

0.44

$* *$ Significant at the 1 percent level; **significant at the 5 percent level; "significant at the 10 percent level.

Note: Numbers in parentheses are robust $z$-statistics. Dependent variable equals 1 if household purchased insurance, 0 otherwise. Weighted probit model. Source: Authors' analysis based on 2004 ICRISAT and World Bank survey data.

village fixed effects, which preclude the use of village-level covariates, are used. Future research by the authors using a much larger sample of villages will include distance to rain gauge. 
The second prediction of the benchmark model is that risk-averse households have a higher willingness to pay for insurance. The results, significant at the 10 percent level, show that risk-averse households are marginally less likely to purchase rainfall insurance. Shifting the risk-aversion parameter from its minimum to maximum value (that is, from 0 to 1 ) reduces the probability of buying insurance by 25 percent (1.1 percentage points). Possible explanations for this result are explored below.

The regression also includes proxies for two other dimensions of the household's utility function: ambiguity aversion and discount rate. Neither of these variables is statistically significant. However, given that these variables are indirectly inferred, it is likely that this result partly reflects measurement error, leading to attenuation bias and weak power to reject the null hypothesis.

Heterogeneous beliefs (bypothesis 2). Households that expect the monsoon to start later will expect a higher payout, because the insurance payout is inversely correlated with rainfall from a fixed calendar date. This measure of pessimism is positively correlated with take-up as predicted; however, it is statistically insignificant. This lack of significance may reflect measurement error in the expectations variable, leading to weak power to reject the null.

Credit constraints (bypothesis 3). Credit constraints, equivalent to low wealth, imply a high shadow value of wealth and less willingness to pay for insurance. The baseline regression includes two wealth variables, $\log (1+$ landholdings) and $\log$ (wealth), both measured at the beginning of the monsoon. Both measures have positive signs, and although neither is individually significant, they are jointly significant at the 2 percent level (see supplemental appendix). These variables are strongly collinear; in an unreported regression excluding log (wealth), the coefficient on land quadruples and becomes statistically significant at the 1 percent level.

The covariates also include a direct proxy for credit rationing, derived from household self-reports about why households do not have one more loan. This coefficient is negative, as predicted, and statistically significant at the 1 percent level. Switching on this variable reduces the probability of take-up by 30 percent (1.4 percentage points).

Trust, financial literacy, and networks (bypothesis 4). Qualitative responses suggest that a significant fraction of households did not fully understand the insurance product and that many relied on recommendations from others for insurance participation decisions. Hypothesis 4 a posits that households with a greater degree of familiarity with or trust in BASIX, the insurance provider, will have higher participation rates. A dummy variable equal to 1 if the household is a member of a borewell user association was created to test this hypothesis. Historically, BASIX has offered group lending to borewell user associations. In 2003, when it first piloted rainfall insurance, it targeted association members. Members of borewell user associations are more likely to know the BASIX sales representative in the village. Such associations also provide a close-knit network of households that share information and advice. 
Membership in a borewell user association has a very large and statistically significant effect on participation decisions: the marginal effects estimates suggest that membership increases the probability of insurance participation by a factor of eight $(p<0.01)$. A second variable indicating whether the household is an existing BASIX borrower at the start of the monsoon also strongly predicts take-up, with BASIX customers 143 percent more likely to purchase insurance $(p<0.01)$. These two variables (along with Gram Panchayat membership) are quantitatively the strongest predictors of insurance participation decisions.

Some evidence suggests the importance of social networks in insurance take-up decisions. Households that are members of the village Gram Panchayat are significantly more likely to purchase insurance $(p<0.01)$ than households that are members of other formal and informal village networks $(p<0.01)$, such as self-help groups, Raithu Mitra groups, and caste committees. A variable that measures the number of other well-known households in the respondent's self-identified primary social group that purchased insurance is positive and statistically significant $(p<0.01)$ : one additional purchasing household among the respondent's primary group raises the probability of the household purchasing insurance by 12 percent.

These results and the qualitative responses discussed earlier suggest that social networks and trust in the insurance provider are key determinants of insurance take-up (hypotheses $4 \mathrm{~b}$ ). Caution should be exercised in interpreting these results, however, because of the possibility that the estimates reflect unobserved heterogeneity across groups (see Manski 1993 for a discussion of this problem in the context of measuring local network effects). In particular, the strength of the findings may in part reflect the approach taken by BASIX in marketing the insurance. BASIX first contacted opinion leaders in the village, asking them to help publicize the product and the marketing meeting. BASIX also reached out to existing customers. The intensity of marketing is thus an omitted variable, which is likely to be correlated with networks and prior experience with BASIX.

Because the intensity of insurance marketing is not directly measured, it is not possible to easily disentangle these two explanations. In ongoing research by the authors a randomized trial is being conducted that controls for the type of marketing and information received by households. (Households are visited by an insurance educator and given an opportunity to purchase insurance policies; various features of the household visit are then randomized.) The estimates here should be viewed as preliminary, pending results from this randomized trial. However, the findings in this article certainly appear at face value to be inconsistent with the full-information benchmark model. All households in the village are eligible to purchase insurance, so in a model in which all households are rational and fully informed, the intensity of insurance marketing should have no effect on insurance participation.

Hypothesis $4 \mathrm{c}$ posits that households vary in their ability to understand the terms of the insurance product. Self-identified "progressive" households-that 
is, farmers whom other villagers ask for advice ( perhaps because they are more knowledgeable or intelligent)_are 14 percent more likely to purchase insurance $(p<0.05)$ than nonprogressive households. Also statistically significantly more likely to purchase insurance are households whose heads are younger $(p<0.01)$ or who have lived outside the village $(p<0.10)$. A doubling of the household head's age reduces the probability of insurance purchase by 32 percent, consistent with the hypothesis that the cost of evaluating new products and technologies is lower for younger people.

Surprisingly, education is not statistically significantly correlated with insurance participation decisions. This result contrasts with that of Gine and Yang (2007), who find that in Malawi education increases the effect of weather insurance provision on the decision to take a crop loan by households. A possible explanation for the difference is that households in Malawi had no prior experience with the insurance provider, while most households in the sample studied here were very familiar with BASIX. The household's opinion of, and trust in, BASIX is thus likely to be relatively more important when evaluating the quality of the insurance product. Another possible explanation for the discrepancy in results is that Giné and Yang study not the decision to purchase insurance per se but the effect of insurance provision on the decision to take out a loan. It is also possible that education is measured with error. If this is the case, there may not be sufficient power to detect the relation between education and insurance take-up (the coefficient, although not significant, has the correct sign).

\section{Risk-Aversion Interaction Effects}

A puzzling finding in table 4 is that risk-averse household are less, rather than more, likely to purchase rainfall insurance-the opposite of the result predicted by the benchmark model. A possible explanation for this result is that risk-averse households are also averse to uncertainty about the insurance policy itself and the potential risks associated with it, given their imperfect understanding of the product.

This hypothesis is tested by interacting risk aversion with three dummy variables indicating the household's familiarity either with BASIX or with the concept of insurance: whether the household belongs to a borewell user association, is a BASIX borrower at the start of the monsoon, and holds any other type of insurance. Under the product uncertainty explanation, one would expect the wrong-signed risk-aversion coefficient to be concentrated among households that are unfamiliar with BASIX or insurance. The specification from table 4 is reestimated with these three additional interaction terms together and then one at a time.

The estimates are consistent with the product uncertainty explanation (table 5). Each interaction term has a positive sign, as predicted, and the coefficients are jointly significant at the 5 percent level. The interaction term Risk aversion $\times$ credit from BASIX is individually significant at the 5 
TABLE 5. Risk-Aversion Interaction Effects

\begin{tabular}{|c|c|c|c|c|}
\hline \multirow[b]{2}{*}{ Variable } & \multirow[b]{2}{*}{ Combined baseline specification } & \multicolumn{3}{|c|}{ Interaction terms added individually } \\
\hline & & 1 & 2 & 3 \\
\hline \multicolumn{5}{|l|}{ Interaction terms } \\
\hline Risk aversion $\times$ borewell user association & $0.005(0.25)$ & $0.024(1.23)$ & & \\
\hline Risk aversion $\times$ credit from BASIX & $0.028(1.74)^{*}$ & & $0.032(2.14) * *$ & \\
\hline Risk aversion $\times$ other insurance & $0.008(0.72)$ & & & $0.014(1.18)$ \\
\hline$F$-test [joint significance, $p$-value] & $0.043 * *$ & & & \\
\hline \multicolumn{5}{|l|}{ Underlying variables } \\
\hline Risk aversion & $-0.024(2.42)^{* * *}$ & $-0.016(2.81)^{* * * *}$ & $-0.018(3.22)^{* * * *}$ & $-0.021(2.17) * *$ \\
\hline Borewell user association & $0.262(1.82)^{*}$ & $0.078(2.84)^{* * * *}$ & $0.344(4.43)^{* * * *}$ & $0.082(4.72)^{* * * *}$ \\
\hline Credit from BASIX & $-0.001(0.08)$ & $0.064(4.73) * * *$ & $-0.003(0.32)$ & $0.066(4.92)^{* * * *}$ \\
\hline Other insurance & $-0.003(0.32)$ & $0.004(1.43)$ & $0.003(1.38)$ & $-0.008(0.79)$ \\
\hline
\end{tabular}

*** Significant at the 1 percent level; ** significant at the 5 percent level; "significant at the 10 percent level.

Note: Numbers in parentheses are robust $z$-statistics. Dependent variable equals 1 if farmer purchased insurance, 0 otherwise. Weighted probit model. Coefficients are normalized to display marginal effects. Regression includes same variables as baseline regression results (other results are not displayed).

Source: Authors' analysis based on 2004 ICRISAT and World Bank survey data. 
percent level when included alone (column 3) and at the 10 percent level when all three interaction terms are included (column 1). The point estimates imply that for a household in which each interaction term is switched from 0 to 1 , the combined coefficient on risk aversion switches from -0.024 to +0.017 . The combined coefficient is not statistically different from zero, however, perhaps because of measurement error in the risk-aversion variable, leading to attenuation bias and weak power to reject the null hypothesis.

A potential source of measurement error is the fact that the risk-aversion variable is measured with respect to a gamble of moderate size. Rabin (2000) argues that risk aversion measured using small gambles is likely to overstate risk aversion applicable to gambles with large payoffs. Using Italian data and exploiting a natural experiment, Bombardini and Trebbi (2007) find a coefficient of relative risk aversion of unity that approximates household behavior for both small and large gambles. Their finding provides support for the approach to measuring risk aversion adopted here. Moreover, it is not necessary to correctly measure the absolute level of risk aversion but only to correctly order the relative degree of risk aversion across households.

\section{Conditional Probit}

As described earlier, BASIX follows a two-step procedure in marketing rainfall insurance. Households are first invited to attend a marketing meeting. Households that attend are then educated about insurance and given the opportunity to purchase policies.

The supplemental appendix presents estimates using a conditional probit model that accounts for the two sequential steps of the insurance participation decision. Two equations are estimated. The first is estimated on the whole sample; it has a dependent variable equal to 1 if the household attends the marketing meeting and 0 otherwise. The second is estimated on the subsample of households that attend the marketing meeting; it has a dependent variable equal to 1 if the household purchases insurance (that is, it measures participation conditional on meeting attendance).

In general, the baseline estimates hold in a similar way across both steps. Members of borewell user associations and BASIX borrowers are both more likely to attend the marketing meeting and more likely to purchase insurance conditional on attendance (statistically significant at least at the 5 percent level). This suggests that the high rates of participation among these groups do not just reflect encouragement by BASIX to attend the meeting, as this mechanism alone would generate selection bias to produce negative coefficients on these variables in the second step. 
Table 6. Average Expenditure on and Maximum Payout from Rainfall Insurance, 2004

\begin{tabular}{lcccc}
\hline Item & $\begin{array}{c}\text { Per policy } \\
\text { (rupees) }\end{array}$ & $\begin{array}{c}\text { Per policyholder } \\
\text { (rupees; based on 1.81 } \\
\text { policies per household) }\end{array}$ & $\begin{array}{c}\text { Percent of liquid } \\
\text { assets at start of } \\
\text { monsoon season }\end{array}$ & $\begin{array}{c}\text { Percent of gross } \\
\text { monsoon farm } \\
\text { revenue }\end{array}$ \\
\hline Insurance expenditure & 200 & 362 & 1.5 & 0.7 \\
Maximum payout & 6,000 & 10,860 & 84.1 & 35.4 \\
\hline
\end{tabular}

Source: Authors' analysis based on 2004 ICRISAT and World Bank survey data.

\section{Other Analysis}

Households on average purchase 1.8 policies, at a cost of Rs 362, corresponding to 1.5 percent of liquid assets at the start of the monsoon season and 0.7 percent of 2004 gross monsoon agricultural revenue (table 6). These numbers are relatively small, consistent with the observation that households are experimenting with a new, imperfectly understood product. (The figures are still nontrivial: in the United States they would be equivalent to expenditure on insurance of $\$ 700-\$ 1,400$ year for a small business owner with annual sales revenue of $\$ 100,000-\$ 200,000$.) Returns on insurance are quite skewed. A maximum payout corresponding to crop failure levels of rainfall across all three phases of the monsoon yields a payout of 35 percent of gross farm revenue for an average household purchasing 1.8 policies.

The large coefficients on members of borewell user associations and BASIX customers raise potential concerns that the strength of other relations may be significantly different across members and nonmembers of the two groups. As a robustness exercise, the baseline results are reestimated on the subsample of households that are not members of borewell user associations or BASIX customers. The point estimates are similar, although the statistical significance of the results is sometimes reduced, reflecting the smaller sample size (results available on request).

\section{Summary and Conclusions}

This article describes an innovative rainfall insurance product offered to smallholder farmers in the Andhra Pradesh region of southern India. The preliminary evidence on the determinants of insurance participation it presents highlight two main deviations from a benchmark model of insurance participation. First, credit constraints appear to be an impediment to purchasing insurance. Households with less land and less wealth, as well as households that report being credit constrained, are less likely to participate in insurance. This result is consistent with the extension of a one-period benchmark model of insurance to include financial constraints. Insurance participation is also increasing in wealth in developed countries, a fact attributed to asymmetric information or fixed 
participation costs (Mulligan and Philipson 2003). The same result is found in a setting in which these explanations appear unlikely to hold.

Second, a variety of results together suggest that limited familiarity with the insurance product plays a key role in participation decisions. Take-up rates are higher among customers of the insurance vendor (BASIX) and members of borewell user associations, who are among BASIX's primary clients. Risk-averse households are less likely to purchase insurance, but only if they are unfamiliar with insurance or with BASIX. Households connected to village networks are more likely to purchase insurance, especially when other members of the household's primary group participate. Respondents who likely have lower cognitive costs of understanding and experimenting with insurance, such as young farmers and self-identified progressive farmers, are more likely to purchase the product. And a significant fraction of households cite advice from other farmers and limited understanding of the product as important determinants of participation decisions.

The finding of the significance of credit constraints has practical implications for insurance contract design. One is that insurance payouts should be made as promptly as possible after rainfall is measured and verified. The survey asked households to identify at which times of the year they are most in need of additional liquid assets; unsurprisingly, households reported being most credit constrained at the start of the sowing season and least constrained in November, when crops are harvested and sold. In 2004 insurance payouts were not paid to farmers until about November. Farmers would benefit if payouts were made available as soon as possible, preferably phase by phase, as each stage of the monsoon is completed. One impediment to early payouts is that the Indian Meteorological Department takes an average of two months to verify rainfall data. ICICI Lombard is setting up a network of automated rain gauges, which should facilitate faster payouts and minimize basis risk.

A second innovation would be to combine insurance with a short-term loan that helps credit-constrained households pay the premium (stated differently, BASIX could offer state-contingent loans). Giné and Yang (2007) study a product of this type. BASIX is reluctant to mix products in this way, because its wants to clearly establish to customers the conceptual difference between insurance and microcredit products.

The insurance product studied here has not yet succeeded in proportionately reaching the most vulnerable households (the poor, credit-constrained households, households that are not members of social networks), which presumably would benefit most from protection against drought. This may partly reflect persistent barriers to trade in insurance, such as credit constraints, but it also may reflect a normal pattern of diffusion of a new product. Early adopters are likely to be households for which the cost of experimenting is low. Participation will then filter through to other households over time.

Morduch (2006) highlights potentially adverse general equilibrium implications of differential rates of insurance participation by rich and poor 
households. He suggests that if rainfall insurance is purchased only by the wealthy, such households may have additional income with which to bid up the price of local nontraded goods during periods of low rainfall, making nonpurchasers worse off. He also suggests that formal insurance may undermine existing risk-sharing mechanisms by raising the threat point of households that seek to withdraw from implicit risk-sharing arrangements.

Relatively little academic research on microinsurance has been conducted to date. Many important questions remain unanswered. Research is needed to determine the causal effect of rainfall insurance on income and consumption smoothing; the price elasticity of demand for insurance (an important policy question given potential government subsidies on insurance contracts); the interaction between rainfall insurance and existing risk-bearing mechanisms; and the pattern of diffusion of insurance participation over time. In ongoing research, the authors are conducting a randomized field experiment among survey households that should shed light on some of these questions.

\section{Appendix. A Simple Model of Insurance Participation UNDER SYMMETRIC INFORMATION}

Consider a risk-averse household with quadratic expected utility of $\mathrm{E}[\mathrm{U}(c)]=$ $\mathrm{E}(c)-\gamma \operatorname{var}(c)$. (This mean-variance form is consistent with a household with constant absolute risk aversion utility facing normally distributed shocks.) Household income is assumed to be $y=y^{*}+e$, where $e$ has zero mean and variance $\sigma_{y}^{2}$. The household has access to an insurance policy that insures against this income volatility $e$.

The timing of events is as follows: The household decides whether to purchase insurance. Income is realized (that is, $e$ is revealed). Insurance payouts if any are made. The household consumes its income $y$ plus any insurance payout.

The policy costs premium $p$. The payout on the insurance is $r=-e+\mu+u$, where $\mu$ is the household's expectation of the average insurance payout and $u$ reflects basis risk associated with the insurance; $u$ has mean 0 and variance $\sigma_{u}^{2}$ (if $\sigma_{u}^{2}=0$ the insurance perfectly offsets the variability in income caused by $e$ ). Thus if the household purchases insurance, it consumes $c=y^{*}+\mu+u-p$; if it does not purchase insurance it consumes $c=y^{*}+e$. Under these assumptions the household's willingness to pay is given by expression (A-1):

$$
p_{\max }=\mu+\gamma\left[\sigma_{y}^{2}-\sigma_{u}^{2}\right] .
$$

Thus the household has a higher willingness to pay if it is more risk averse (higher $\gamma$ ), the insurance involves a lower basis risk (lower $\sigma_{u}^{2}$ ), the insured risk is larger (higher $\sigma_{y}^{2}$ ), or the expected payout of the insurance is higher (higher $\mu$ ). 


\section{Credit Constraints}

Now consider a simple extension of this model that introduces credit constraints. Assume that farmers begin with wealth $W$, which they may use either to purchase insurance or invest in seeds. The investment in seeds determines household income; mean household income $y^{*}=\mathrm{f}(I)$ where $I$ is investment in seeds and $f($.$) is concave. Households are unable to borrow against their future$ income to purchase seeds or buy insurance $(W \geq I+p)$. Any wealth not used for insurance or seeds is assumed to be stored at an interest rate of zero.

If the household has a high level of wealth, it will simply invest up to the point at which $\mathrm{f}^{\prime}(I)=1$. In this case willingness to pay for insurance is given by equation (A-1). Participation is independent of $W$, reflecting the fact that the household has constant absolute risk aversion utility.

In the region where $W$ is low and credit constraints bind, the household decides whether or not to purchase the insurance and invests all residual wealth in seeds. If the household purchases insurance, investment is $I=W-p$, and household consumption is $c=\mathrm{f}(W-p)+\mu+u$. If the household does not purchase insurance, investment in seeds is given by $I=W$, and consumption is $c=f(W)+e$. Taking expectations of these two expressions, the household's willingness to pay is given implicitly by

$$
\mathrm{f}(W)-\mathrm{f}\left(W-p_{\max }\right)=\mu-\gamma\left[\sigma_{y}^{2}-\sigma_{u}^{2}\right] .
$$

The left side of the equation is equal to $\int_{W-p}^{W} f^{\prime}(x) d x$. Because $f($.$) is concave,$ $f(W)-f(W-p)$ is decreasing in $W$. Therefore $d p_{\max } / d W>0$, (that is, the willingness to pay for insurance is increasing in wealth). Also, because $f^{\prime}(W)>1$, $p_{\max }$ is lower in the region in which credit constraints bind than in the region where they do not.

\section{Summary of Results}

This simple model of insurance participation under symmetric information predicts that willingness to pay for insurance will be higher when risk aversion is high (high $\gamma$ ), the risk to be insured is large (high $\sigma_{y}^{2}$ ), the basis risk is low (low $\sigma_{u}^{2}$ ), the actuarial value of the insurance is high (high $\mu$ ), and the household is less credit constrained (the shadow value of $W$ is low).

\section{REFERENCES}

Abbring, Jaap H., Pierre-André Chiappori, and Jean Pinquet. 2003. "Moral Hazard and Dynamic Insurance Data.” Journal of the European Economic Association 1(4):767-820.

Bombardini, Matilde, and Francesco Trebbi. 2007. "Risk Aversion and Expected Utility Theory: An Experiment with Large and Small Stakes." Working Paper, University of British Columbia, Vancouver, and Harvard University, Cambridge, Mass.

Cawley, John, and Tomas Philipson. 1999. "An Empirical Examination of Information Barriers to Trade in Insurance.” American Economic Review 89(4):827-46. 
Cole, Shawn, Jeremy Tobacman, and Petia Topalova. 2008. "Weather Insurance: Managing Risk through an Innovative Retail Derivative." Working Paper, Harvard Business School, Cambridge, Mass.; Oxford University, Oxford, U.K.; and the International Monetary Fund, Washington, D.C.

Cole, Shawn, and Peter Tufano. 2007. "BASIX." Case 9-207-299, Harvard Business School, Cambridge, Mass.

Feder, Gershon, Richard E Just, and David Zilberman. 1985. "Adoption of Agricultural Innovations in Developing Countries: A Survey." Economic Development and Cultural Change 33(2):255-98.

Gadgil, Sulochana, P.R. Seshargiri Rao, and K. Narahari Rao. 2002. "Use of Climate Information for Farm-Level Decision Making: Rainfed Groundnut in Southern India." Agricultural Systems 74(3):431-57.

Giné, Xavier, Helene Lilleor, Robert Townsend, and James Vickery. 2005. "Weather Insurance in Semi-arid India." Working Paper. World Bank, Development Economics Research Group, Washington, D.C.

Giné, Xavier, Robert Townsend, and James Vickery. 2007. "Statistical Analysis of Rainfall Insurance Payouts in Southern India." American Journal of Agricultural Economics 89(5):1248-54.

Giné, Xavier, and Dean Yang. 2007. "Insurance, Credit and Technology Adoption: Field Experimental Evidence from Malawi.” Working Paper. World Bank, Development Economics Research Group, Washington, D.C., and Department of Economics, University of Michigan, Ann Arbor.

Griliches, Zvi. 1957. "Hybrid Corn: An Exploration in the Economics of Technical Change." Econometrica 25(4):501-22.

Hess, Ulrich. 2002. "Innovative Financial Services for India, Monsoon-Indexed Lending and Insurance for Smallholders.” Working Paper 9, World Bank, Agricultural Research Department, Washington, D.C.

Kalavakonda, Vijay, and Olivier Mahul. 2004. "Crop Insurance in Karnataka.” Working Paper, World Bank, Financial Sector Operations and Policy Department, Washington, D.C.

Lim, Youngjae, and Robert Townsend. 1998. "General Equilibrium Models of Financial Systems: Theory and Measurement in Village Economies." Review of Economic Dynamics 1(1):59-118.

Manski, Charles. 1993. "Identification of Endogenous Social Effects: The Reflection Problem." Review of Economic Studies 60(3):531-42.

Manski, Charles, and Steven Lerman. 1977. "Estimation of Probabilities from Choice- Based Samples." Econometrica 45(8):1977-88.

Mishra, P.K. 1996. Agricultural Risk, Insurance and Income. A Study of the Impact and Design of India's Comprehensive Crop Insurance Scheme. Arabury, Vermont: Avebury Ashgate Publishing.

Morduch, Jonathan. 1995. "Income Smoothing and Consumption Smoothing." Journal of Economic Perspectives 9(3):103-14.

— 2006. "Micro-insurance: The Next Revolution?" In Abhijit Banerjee, Roland Benabou, and Dilip Mookherjee, eds., Understanding Poverty. New York: Oxford University Press.

Mulligan, Casey, and Tomas Philipson. 2003. "Insurance Market Participation under Symmetric Information." Working Paper, Department of Economics, University of Chicago.

Rabin, Matthew. 2000. "Risk Aversion and Expected Utility Theory: A Calibration Theorem." Econometrica 68(5):1281-92.

Rothschild, Michael, and Joseph Stiglitz. 1976. "Equilibrium in Competitive Insurance Markets: An Essay on the Economics of Imperfect Information." Quarterly Journal of Economics 90(4):630-49.

Townsend, Robert. 1994. "Risk and Insurance in Village India." Econometrica 62(3):539-92.

World Bank. 2005a. "Drought in Andhra Pradesh: Long-Term Impact and Adaptation Strategies." Working Paper, South Asia Environment and Social Development Department, Washington, D.C.

- 2005b. Managing Agricultural Production Risk: Innovations in Developing Countries. Washington, D.C.: World Bank. 